\title{
MECHANICAL TESTING OF COMPOSITE SPECIMENS MADE BY RFI TECHNOLOGY
}

\author{
L. Křípal
}

Brno University of Technology, Faculty of Mechanical Engineering, Institute of Aerospace Engineering, Technická 2896/2, 61669 BRNO, Czech Republic. E-mail: canadian@centrum.cz. Received 2006-10-16, accepted 2007-03-20

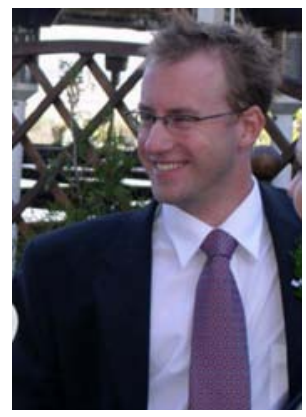

\author{
Lukáš KŘíPAL, Eng. \\ Date of birth: 1980. \\ Education: 1995-1999 - Ceramics Technical High School, analytical chemistry. 1999-2004 - University of Technology \\ Brno, Chemical faculty, engineer of material chemistry. 2004-2007 - University of Technology Brno, Faculty of \\ Mechanical Engineering, academic title. \\ Affiliations and functions: 1997-1998 - lab. worker at analytical lab. at River-basin Ohře Corp.; 2002-2004 - 3 years \\ unskilled research laborer at University of Technology Brno, Chemical faculty; 2002 - external partnership at PREFA \\ COMPOSITES Corp.; 2006 - external partnership at University of Defence Brno. \\ Field of research: mechanical testing of composite materials, Resin film infusion technology (RFI). \\ Present position: 2007 - 3 years research laborer at Aerospace Research Centre at University of Technology Brno, \\ Faculty of Mechanical Engineering. \\ Publications: author of 8 articles, 4 conference presentations.
}

\begin{abstract}
The present paper provides a description of the RFI (Resin Film Infusion) method and influence of the polymer epoxy systems and their reinforcements on the mechanical properties of the whole composite specimen.

Typically, the RFI element consists of a thermoset resin film placed between one side of a metal tool and a dry textile fiber preform. Then, a bag connected to a vacuum pump and processed under a selected thermal curing cycle closes the whole system. RFI technology has gone through some changes since it was discovered. One of the RFI varieties is LF-Technology (Letoxit Foil) provided by local Czech producer 5M Ltd. LF Technology, developed and patented by 5M Ltd., is a very efficient technique for producing sophisticated and relatively cheap composite structures.

Part A: The composite specimens were prepared from various types of reinforcements and matrices, as noted below. The basic experimental part of the research program was focused on the property verification of two polymer epoxy matrix systems applicable to RFI technology. Glass (plain and twill weave), carbon (plain and twill weave), hybrid - Carbon/Kevlar (plain weave) and basalt (plain weave), reinforcements were used. In the experimental part of this work, tests on the mechanical properties were made. These properties (Flexural strength, interlaminar shear strength [ILSS] and impact toughness) were chosen because of their fast orientation in material properties and the state of the finished composite part. Test specimens were prepared by $5 \mathrm{M}$ Ltd. Borsice $\mathrm{u}$ Buchlovic, Czech Republic, Europe.

Part B: Other samples of hybrids (Basalt/Kevlar) and UD (unidirectional) composites were fabricated and tested at the IAE (Institute of Aerospace Engineering), Brno University of Technology. The epoxy resin foils LFX023, LFX032 and LFX035 were applied.

Part C: In this part unidirectional (UD) materials were tested. Thanks to the resin properties it was easy to get clear material after selecting the right curing cycle.

LF Technology gives freedom to designers, helps push down prices of composite products and increases properties and reliability, which is supported by favorable responses from customers and quick and relatively easy development of new products. All these advantages promise a very good future for LF Technology [9].
\end{abstract}

Keywords: RFI technology, mechanical testing, LF-Technology.

\section{Introduction}

In recent years, the resin film infusion has gained popularity for the manufacture of structural polymerbased composites for aerospace, automotive, and military applications. RFI (Resin Film Infusion) has been identified as an alternative cost-effective manufacturing technology to RTM and the conventional autoclave prepreg technique. The production cycle is usually performed in the autoclave under increased temperature and pressure, where the fiber infiltration and the composite consolidation occur in a single step process. Typically, the RFI element consists of a thermoset resin film placed between one side of a metal tool and a dry textile fiber preform. Problems with conventional RFI appear if sandwich structures are manufactured; honeycombs are filled with resin and foam which prevents impregnation of the sandwich skin on the opposite site of the resin layer.

Concerning these disadvantages of conventional processes and a need for universal low cost technology, 
$5 \mathrm{M}$ Ltd. developed and patented a very efficient technique for production of sophisticated and relatively cheap composite structures, which is called Letoxit Foil Technology (LF Technology). LF Technology is based on laying dry reinforcement and core material in the mould with layers of foil polymer material - commercial name Letoxit Foil. The entire composition is vacuumbagged and cured at an elevated temperature. The scheme can be seen in figure 1. The finished part is released from the mould as a ready to use product with an excellent surface. The variability of LF Technology gives freedom to design composite parts at a very competitive price. Autoclave can be employed but is not necessary, as vacuum assistance is usually enough for reinforcement impregnation [9].
The basic component for LF Technology is Letoxit Foil, which is usually a thermoset flexible film. The basic type is Letoxit Foil LFX 023, which is a composition of special epoxy resin hardeners that are latent at room temperature. The film color is originally light yellow but can be set according to the customer desire. The thickness of Letoxit Foil varies between 0.1 and $0.7 \mathrm{~mm}$ and is described by the area weight, which is usually between $100 \mathrm{~g} / \mathrm{m}^{2}$ and $700 \mathrm{~g} / \mathrm{m}^{2}$.

Alongside LFX 023, there are several other types of Letoxit Foils available. Some of them are listed in the table bellow (Tab. 1) [9].

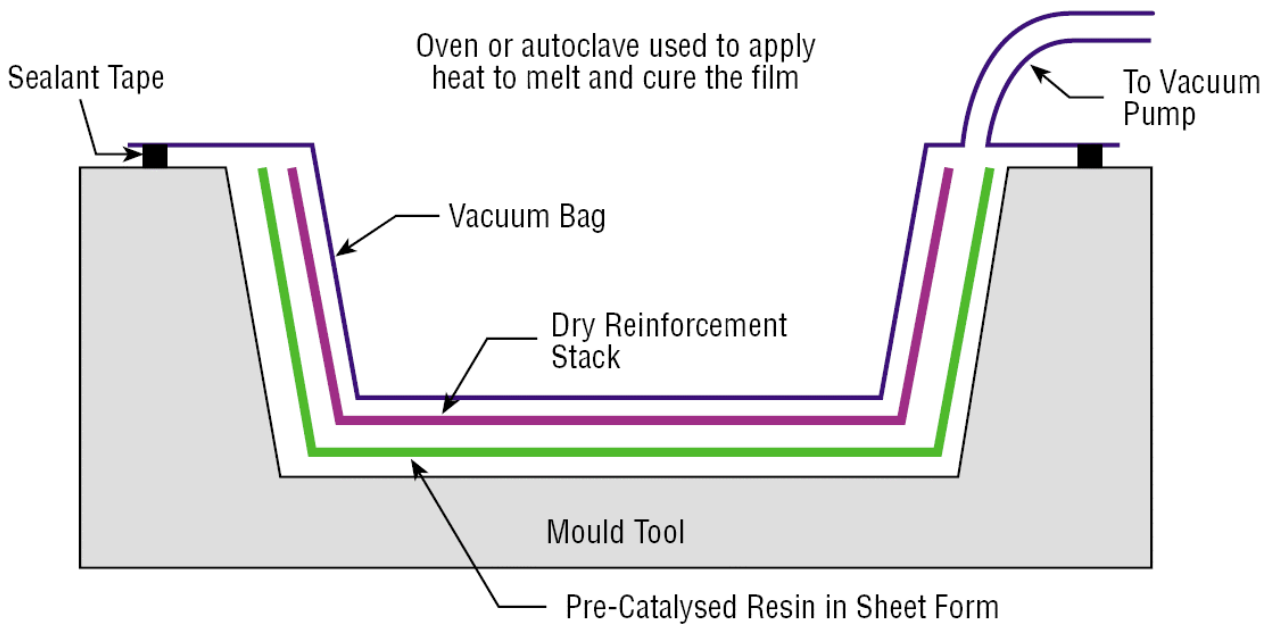

Fig 1. Scheme of RFI technology

Table 1. Commonly used Letoxit Foil types

\begin{tabular}{|c|c|c|}
\hline Name & Resin type & Advantage \\
\hline LFX023 & EPOXY & Basic type \\
\hline LFX033 & EPOXY & Fast curing \\
\hline LFX036 & EPOXY & $\mathrm{T}_{\mathrm{g}}$ above $150^{\circ} \mathrm{C}$ \\
\hline LFX037 & Modified EPOXY & High impact strength \\
\hline LFX038 & Halogenated EPOXY & Fire retardant \\
\hline LFX040 & Modified CYANOESTER & $\mathrm{T}_{\mathrm{g}}$ up to $250^{\circ} \mathrm{C}$ \\
\hline LFX035 & EPOXY & Viscous \& tacky - ideal for UD reinf. \\
\hline
\end{tabular}

The main advantage of LF Technology is the variability of reinforcement due to very simple impregnation. Also, a combination of different reinforcement types is possible. The most common reinforcements are fabrics, where glass, carbon, aramid and basalt are usually used. Also hybrids of these materials are possible. The most important parameters of fabrics for LF Technology are area, weight, thickness and size.

The main difference between LF Technology and standard RFI consists in the sandwich structure production, as in the case of prepregs. Almost all types of core material used for sandwich structures of thermoset composites can be chosen. The most popular are honeycombs, foams and special core materials such as SORIC, COREMAT etc. Core materials can be applied locally in the composite if an increase in stiffness of a certain area of the composite part is required. This approach easily excludes ribbon necessity. LF Technology also gives the possibility of one-shot application of local reinforcements. Typical examples are metal ribbons or pulled profiles and inserts for screw and rivet fastenings made from steel, aluminum or composite [8]. 


\section{Testing conditions}

The 3-point flexure test was performed according to international testing standard - ISO 178. This scheme can be seen in figure 2 .

- Test specimen's size: $\mathrm{h} \times \mathrm{b} \times 1=3 \times 15 \times 65[\mathrm{~mm}]$

- Support width: $1_{\mathrm{v}}=50 \mathrm{~mm}$

- Support radius: $\mathrm{R}_{\mathrm{p}}=2 \mathrm{~mm}$

- Loading pike radius: $\mathrm{R}_{\mathrm{t}}=5 \mathrm{~mm}$

- Testing machine INSTRON, loading velocity $2 \mathrm{~mm} / \mathrm{min}$

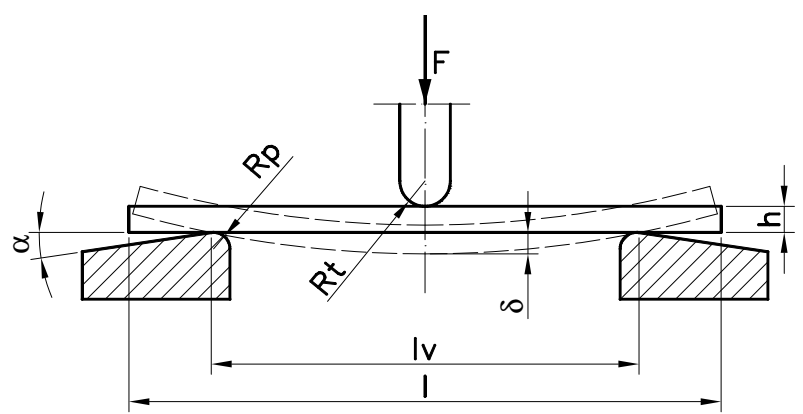

Fig 2. 3-point flexure test scheme

Interlaminar shear strength was conducted in accordance with ASTM, designated D2344-84.

- Test specimen's size: h x b x $1=3 \times 15 \times 20$ [mm]

- Support width: $1_{\mathrm{v}}=13 \mathrm{~mm}$

- Support radius: $\mathrm{R}_{\mathrm{p}}=2 \mathrm{~mm}$

- Loading pike radius: $\mathrm{R}_{\mathrm{t}}=2 \mathrm{~mm}$

- Testing machine INSTRON, loading velocity $1 \mathrm{~mm} / \mathrm{min}$.

The impact strength was tested according to the Charpy impact test, designated ISO 179, noninstrumented part. Specimens were 80 x $10 \mathrm{~mm}$ thick. The specimens were un-notched.

Each test series had 10 testing specimens.

\section{Part A: Common classic fabrics}

Various classic fabrics along with 2 epoxy systems (Letoxit Foil LFX023 and Letoxit Foil LFX032 toughened epoxy resin films) were tested and compared. In figures 3 and 4 similar standard curing cycles are shown. The testing specimens were composed of 12 layers of fabric and 8 layers of epoxy resin film.

Figures 5 and 6 show the flexural modulus and strength of composite samples made by Resin Film Infusion technology (Letoxit Foil technology by $5 \mathrm{M}$ Inc.).
Table 2. Used materials

\begin{tabular}{|c|}
\hline Reinforcing materials: \\
\hline Carbon (plain and twill weave) fabric $200 \mathrm{~g} / \mathrm{m}^{2}$ \\
\hline $\begin{array}{l}\text { Glass (plain and twill weave) fabric } 211 \mathrm{~g} / \mathrm{m}^{2} \\
\qquad 200 \mathrm{~g} / \mathrm{m}^{2}\end{array}$ \\
\hline Basalt (plain weave) fabric $210 \mathrm{~g} / \mathrm{m}^{2}$ \\
\hline $\begin{array}{l}\text { Hybrid carbon/Kevlar }{ }^{\circledR} \text { fabric (plain w.) fabric } \\
\qquad 160 \mathrm{~g} / \mathrm{m}^{2}\end{array}$ \\
\hline Matrix materials: \\
\hline EPOXY pre-catalyzed resins in foil form \\
\hline Letoxit Foil LFX023 \\
\hline Letoxit Foil LFX032 \\
\hline
\end{tabular}

Curing cycles

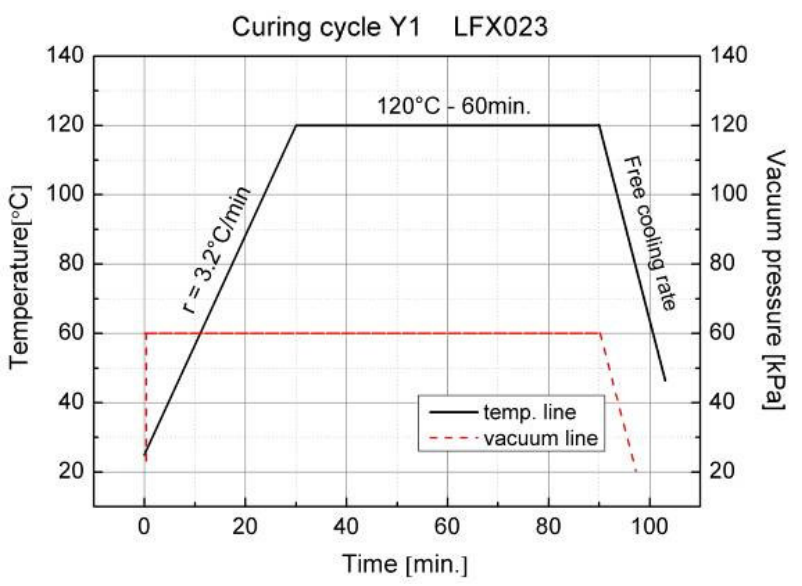

Fig 3. Curing cycle Y1 for LFX023

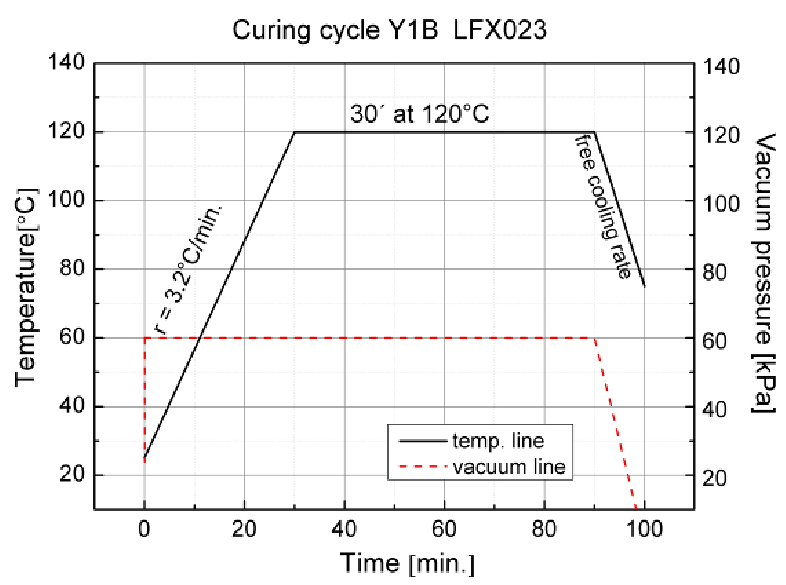

Fig 4. Curing cycle YB1 for LFX023

The typical curing conditions are $120^{\circ} \mathrm{C}$ for 1 hour but LFX 023 can be cured at any temperature between $90^{\circ} \mathrm{C}$ and $130^{\circ} \mathrm{C}$. 
Mechanical properties

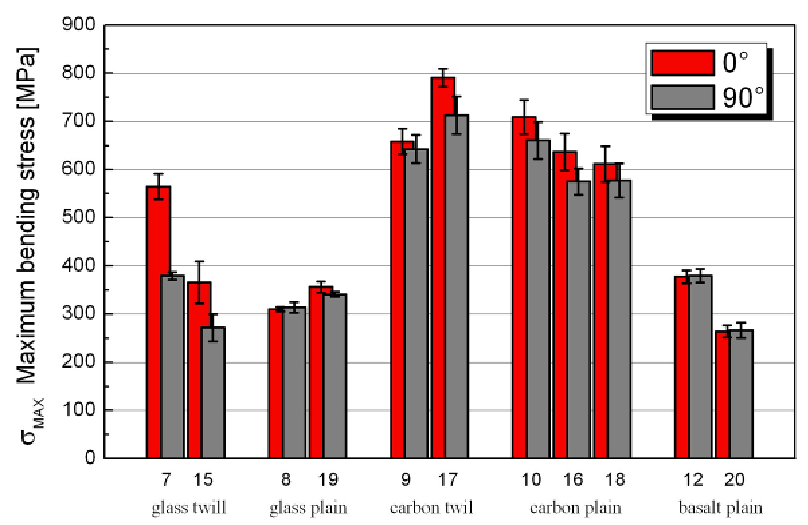

Fig 5. Maximum flexural stress

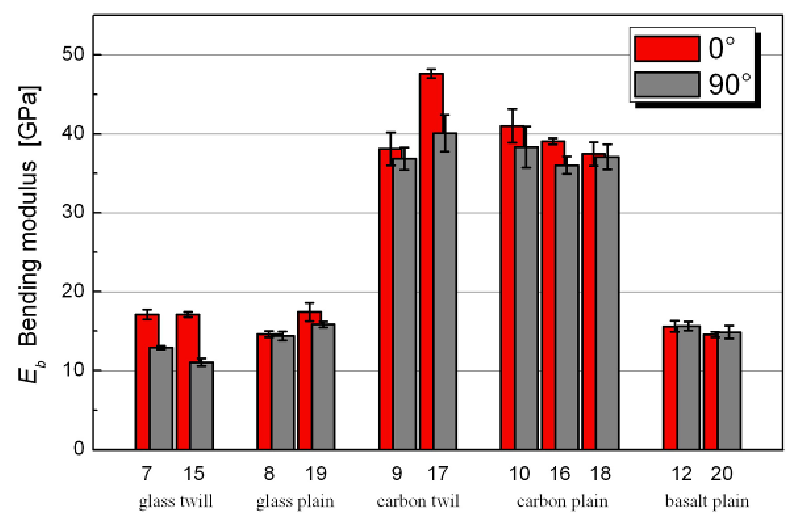

Fig 6. Flexural modulus

The bending modulus along the fiber $\left(0^{\circ}\right)$ : was highest with plain carbon reinforcement contra, the lowest value of plain glass reinforcement.

The bending modulus across the fiber $\left(90^{\circ}\right)$ : good flexural strength of carbon plain reinforcement and low properties were registered with twill glass reinforcement. The highest flexural modulus had twill carbon weave.

It is interesting to compare the plain glass weave and basalt plain weave on the grounds of eventual replacement of glass behind the basalt (from a costeffective and mechanical standpoint). In figure 5 we can see the difference. Basalt along the fiber and across the fiber had better results than glass reinforcement.

The interlaminar shear strength is largely dependent on matrix properties. In figure 7 we can see the highest values for carbon plain weave $(60.31 \pm 2.46 \mathrm{MPa})$ and the lowest for glass plain weave $(44.88 \pm 2.91 \mathrm{MPa})$. The standard epoxy matrix LFX 023 with LFX 032 epoxy system were compared. In figure 7 we can see results of ILSS testing of both epoxy resin systems where LFX 023 shown higher values of mechanical properties.

Plain weave glass vs. basalt (with LFX023) was comparable. Twill weave carbon vs. glass (with LFX023) was also comparable [3].

The ILS strength of the composites made of the epoxy film resin LFX 023 is higher than that of the composite made from the epoxy film resin LFX 032, respectively. Overall, it is possible to say that the matrix system with LFX023 is, at result level, more reproducible and it is preferable to manufacture composites using the RFI process with this type of resin. Optimal mechanical properties (flexural and interlaminar - ILSS) are guaranteed by low void content and defects, etc. [4].

Figure 8 shows the impact test result for plain fabrics. The basalt and glass reinforcements showed the highest impact strength.

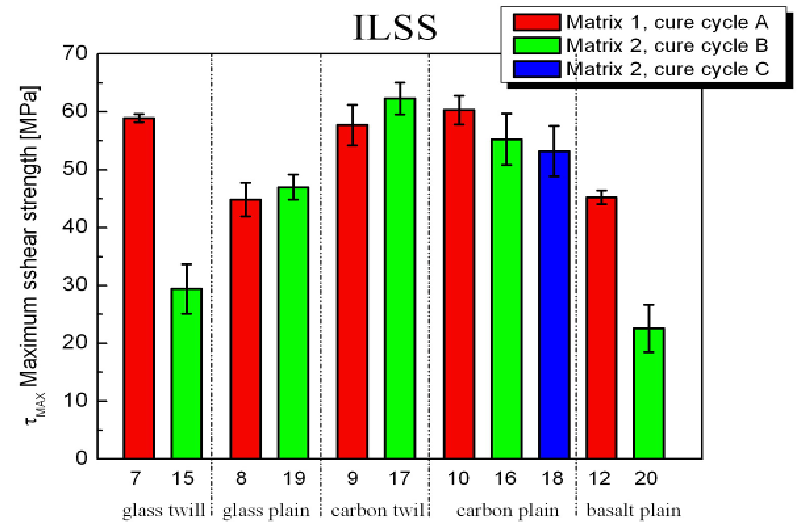

Fig 7. Interlaminar shear strength

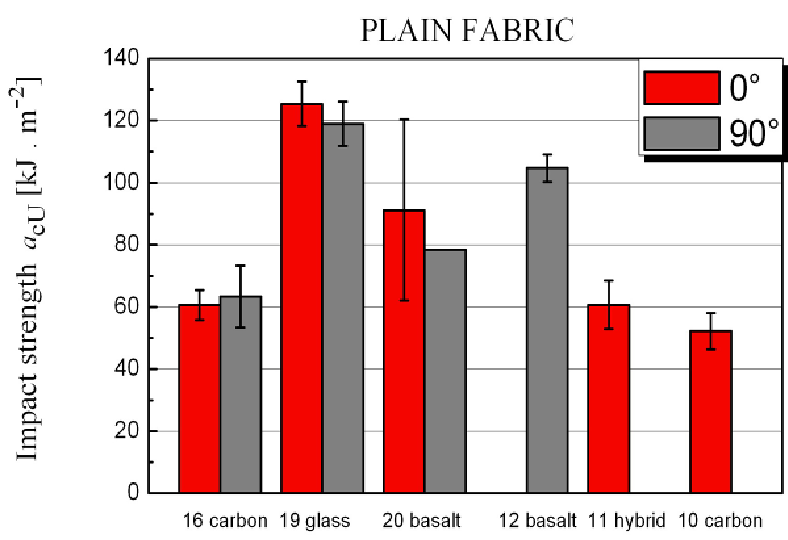

Fig 8. Impact strength

\section{Part B: Hybrid fabrics}

Recently in terms of non-availability of carbon reinforcements, it was the aim of this part of the research to investigate the mechanical properties of hybrid basalt/Kevlar fabrics as an alternative to use basalt instead of carbon in hybrid fabrics. In terms of price and design, basalt appeared to be an acceptable material (Tab. 3 ). The testing specimens were composed of 16 layers of fabric and 8 layers of epoxy resin film (this set-up is used for hybrid samples only!).

Table 3. Used materials

\begin{tabular}{|l|}
\hline Reinforcing materials: \\
\hline Carbon/Kevlar® (plain and weave) fabric $160 \mathrm{~g} / \mathrm{m}^{2}$ \\
\hline Basalt/Kevlar@ (plain weave) fabric $220 \mathrm{~g} / \mathbf{m}^{2}$ \\
\hline Matrix materials: \\
\hline EPOXY pre-catalyzed resin in foil form - Letoxit Foil \\
LFX023
\end{tabular}


Composite samples were composed of 12 layers of fabrics (glass, carbon and basalt), 16 layers of hybrid fabrics and 8 layers of epoxy resin LFX023.

\section{Curing cycle}

For preparation of hybrid composite testing specimens the standard curing cycle was selected.

\section{Mechanical properties}

The flexural properties data below, gives information about each single type of reinforcement used in hybrid fabrics. They were taken from part $\mathrm{A}$ and compared to the hybrid (basalt/Kevlar and carbon/Kevlar) samples (Fig 9 and 10).

Flexural properties of hybrids and their subcomponents

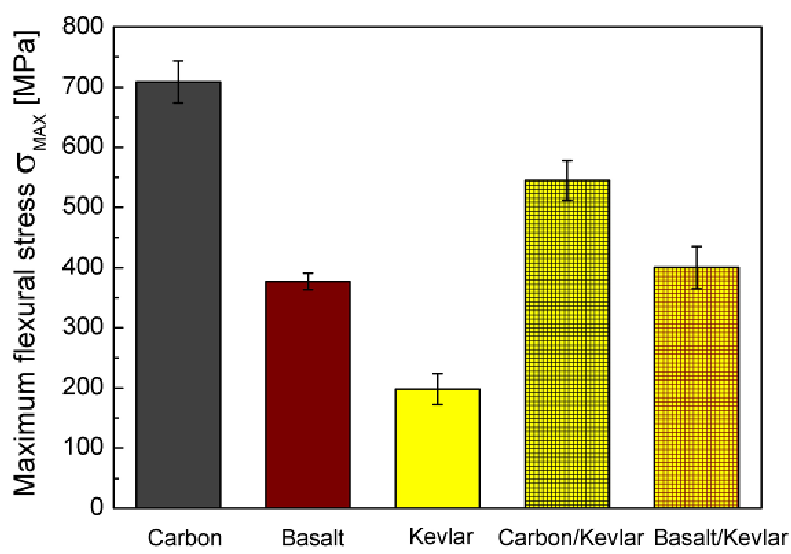

Fig 9. Maximum flexural stress

Flexural properties of hybrids and their subcomponents

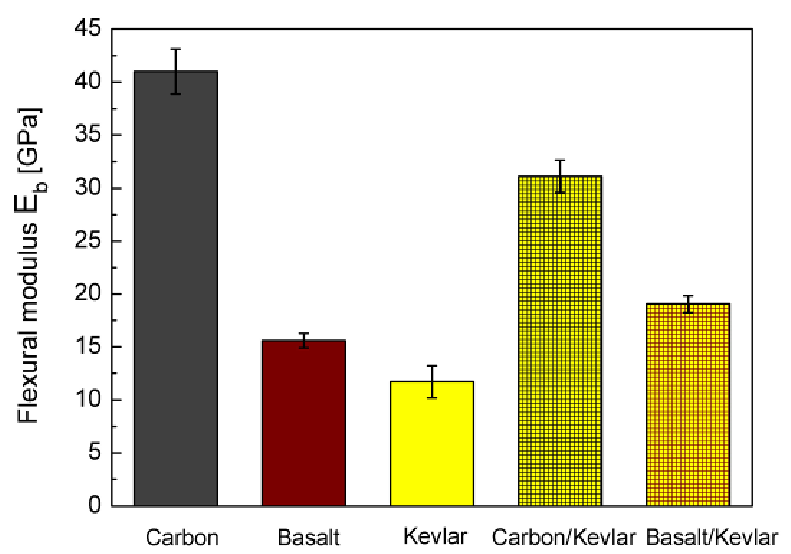

Fig 10. Flexural modulus

From the obtained flexural data we can see the highest flexural modulus of the carbon sample in contrast to the lowest of the Kevlar sample.

Interlaminar shear strength is similar to measured flexural data (as shown in figure 11). Basalt samples and hybrid (Basalt/Kevlar) showed the best impact strength properties, over $100 \mathrm{~kJ} / \mathrm{m}^{2}$, (Fig 12) [7].

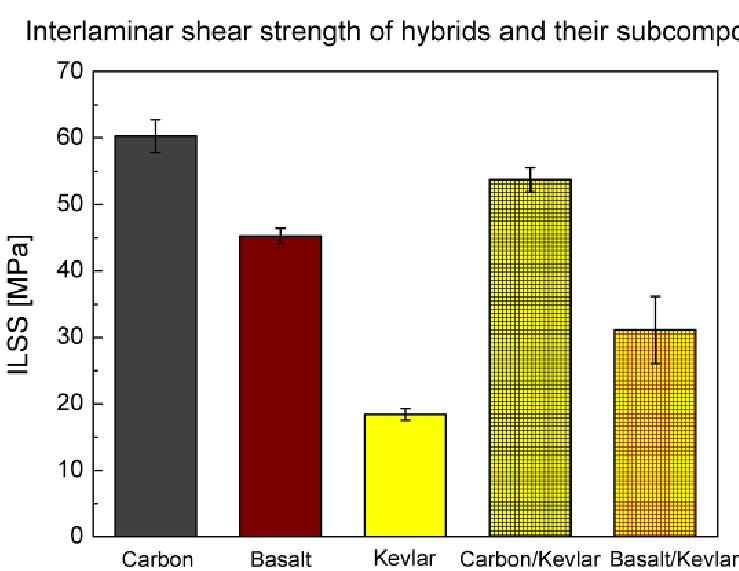

Fig 11. Interlaminar shear strength Impact strength of hybrids and their subcomponents

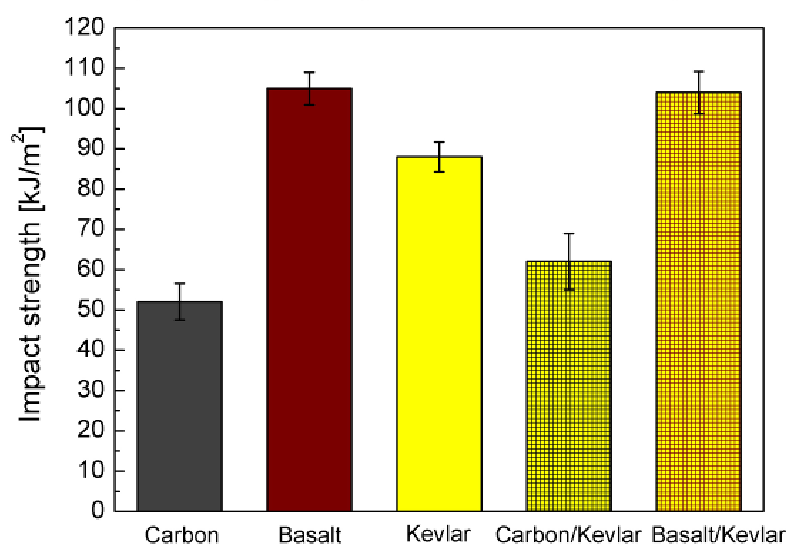

Fig 12. Impact strength

\section{Part C: Unidirectional Fabrics}

The unidirectional fabrics were tested with new LFX035 RFI epoxy film resin which is more liquid hence more suitable for the RFI infusion process where UD textiles do not wet out well (LFX035 was compared to LFX023) (Tab. 4). Curing cycles are described below and shown in figure 13. The test specimens were composed of five layers of fabric and six layers of epoxy resin film.

Table 4. Used materials

\begin{tabular}{|c|}
\hline Reinforcing materials: \\
\hline Glass unidirectional fabric Interglas $92145 \mathbf{2 2 0} / \mathbf{m}^{2}$ \\
\hline Carbon unidirectional fabric $140 \mathrm{~g} / \mathbf{m}^{2}$ \\
\hline Matrix materials: \\
\hline EPOXY pre-catalyzed resin in foil form \\
\hline Letoxit Foil LFX023 \\
\hline Letoxit Foil LFX035 \\
\hline
\end{tabular}


Curing cycles
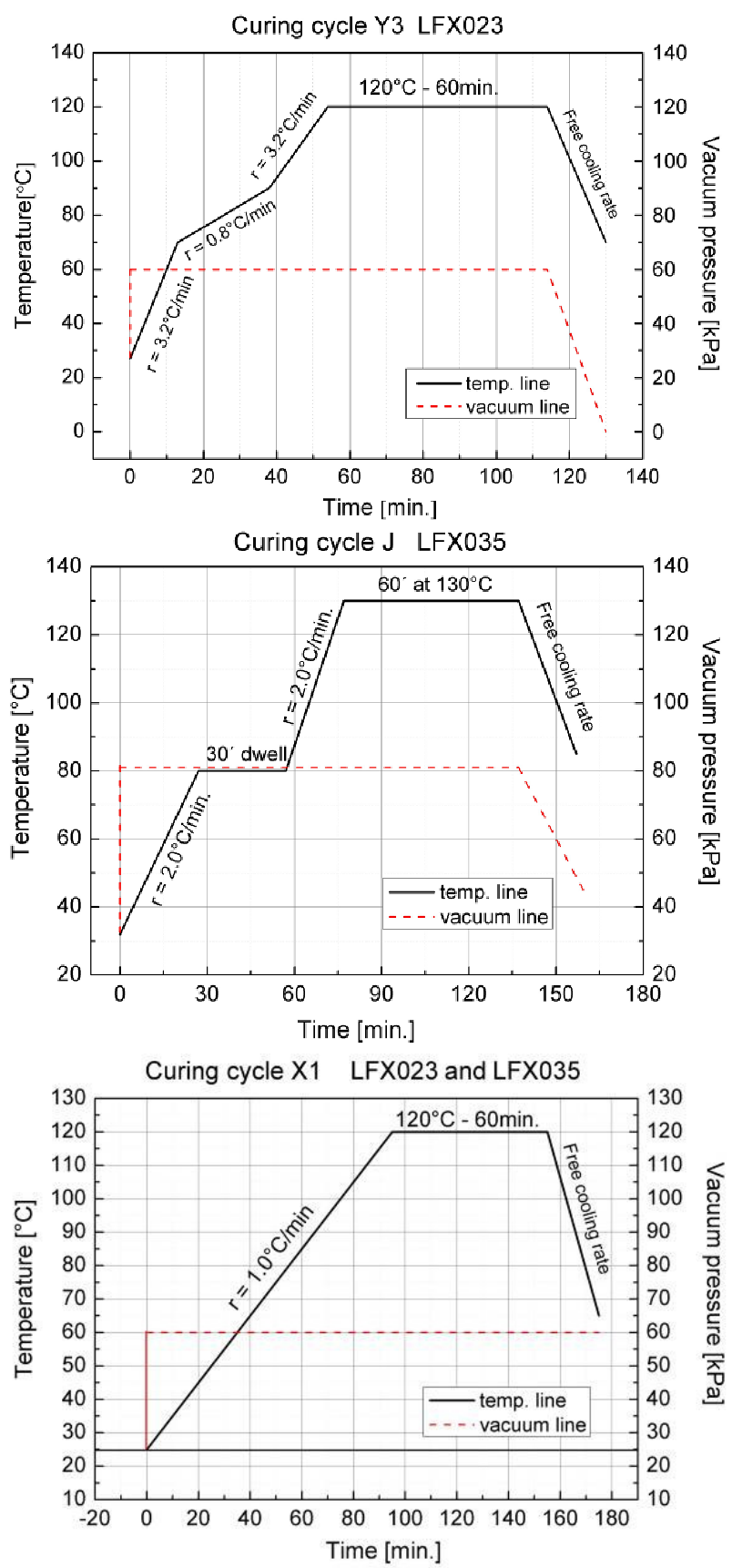

Fig 13. Curing cycles $\mathrm{Y} 3$, $\mathrm{J}$ and $\mathrm{X} 1$ for LFX023 and LFX035

The ramp of curing cycle $\mathrm{J}$ was $2^{\circ} \mathrm{C} / \mathrm{min}$ with a 30 min dwell at $80^{\circ} \mathrm{C}$. Cycle $\mathrm{X} 1 \mathrm{ramp}$ was $1^{\circ} \mathrm{C} / \mathrm{min}$.

\section{Mechanical properties}

For epoxy resin LFX023 was optimized curing cycle signed as Y3. After resin strips application results were significantly better Y3 curing cycle was optimized for LFX023 epoxy resin film (Fig 14-15). Better mechanical results can be achieved after application of resin strips in combination with dry UD reinforcement.

Maximum flexural stress for glass reinforcement Interglass $92145220 \mathrm{~g} / \mathrm{m}^{2}$ was $794,4 \pm 63,8 \mathrm{MPa}$ and for flexural modulus was $26,7 \pm 1,6 \mathrm{GPa}$, which is in comparison to commercial technologies almost equivalent (Maximum flexural stress $810 \mathrm{MPa}, \mathrm{R} \& \mathrm{G}$ ) (Fig 22).

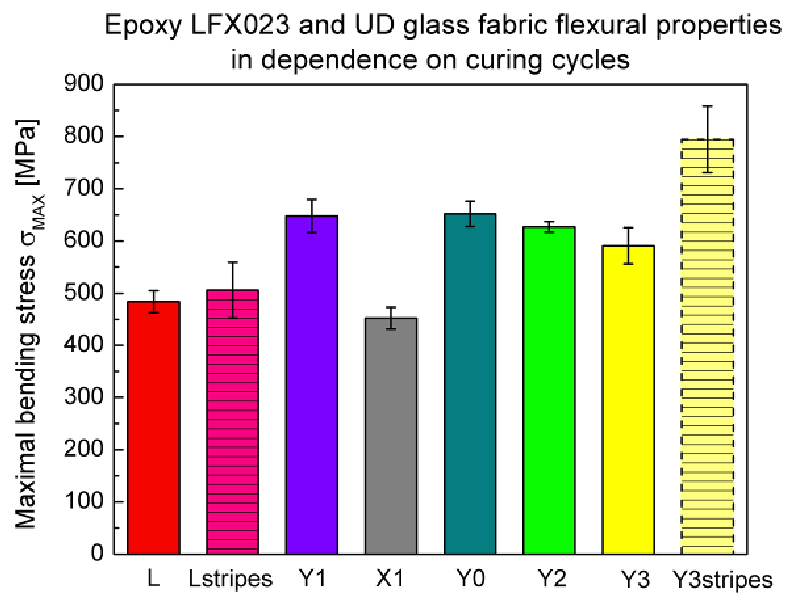

Fig 14. Maximum flexural stress - LFX023+glass UD

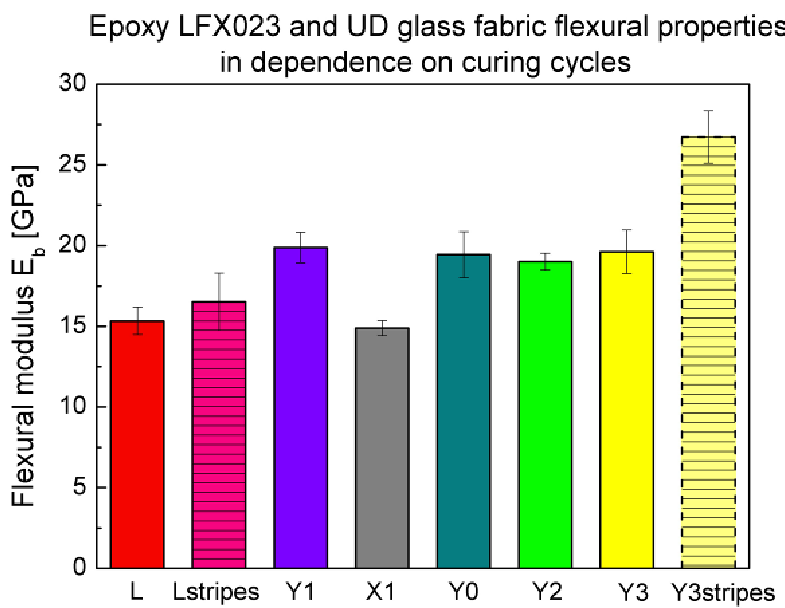

Fig 15. Flexural modulus - LFX035+glass UD

Epoxy LFX035 and UD glass fabric flexural properties in dependence on curing cycles

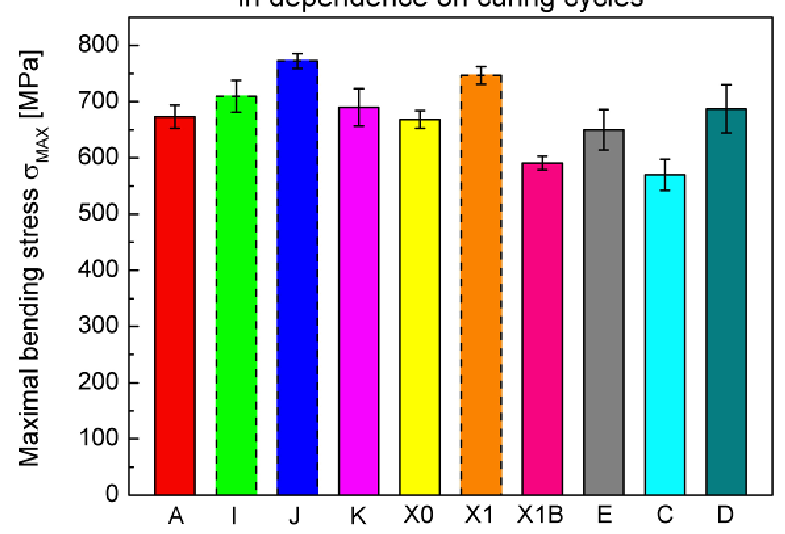

Fig 16. Maximum flexural stress - LFX035+glassUD

Maximum flexural stress for glass reinforcement Interglass $92145220 \mathrm{~g} / \mathrm{m}^{2}$ was $772,6 \pm 13,1 \mathrm{MPa}$ and flexural modulus was $24,4 \pm 0,9 \mathrm{GPa}$ (curing cycle J), which is in comparison to commercial technologies 
almost equivalent (Maximum flexural stress $810 \mathrm{MPa}$, $R \& G)$, shown in figures 16 and 17.

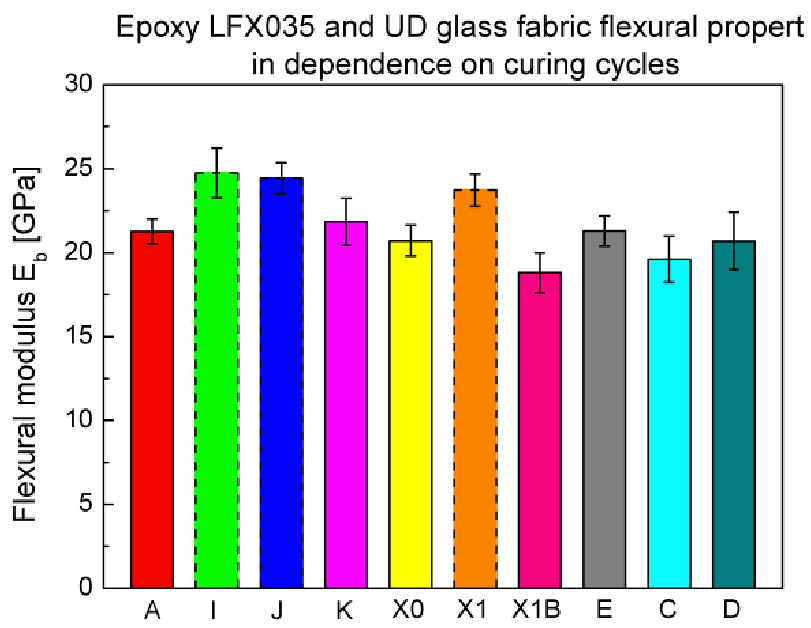

Fig 17. Flexural modulus - LFX035+glassUD

Epoxy LFX035 and UD carbon fabric flexural properties

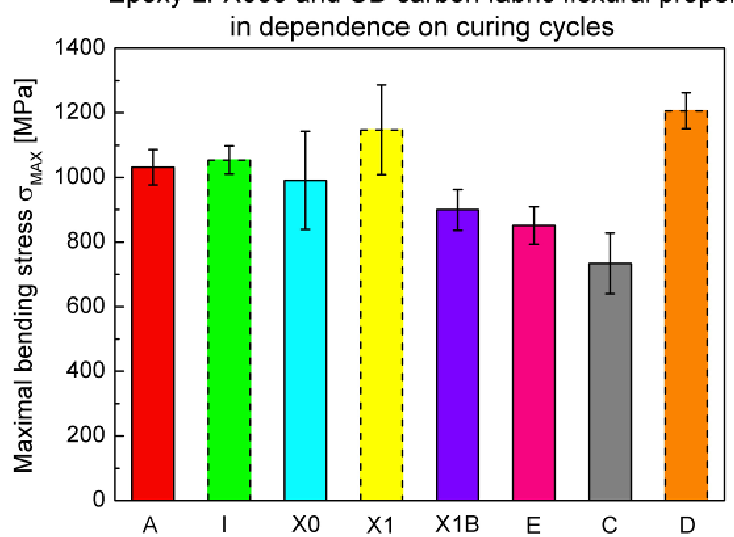

Fig 18. Maximum flexural stress - LFX035+carbon UD

Epoxy LFX035 and UD carbon fabric flexural properties in dependence on curing cycles

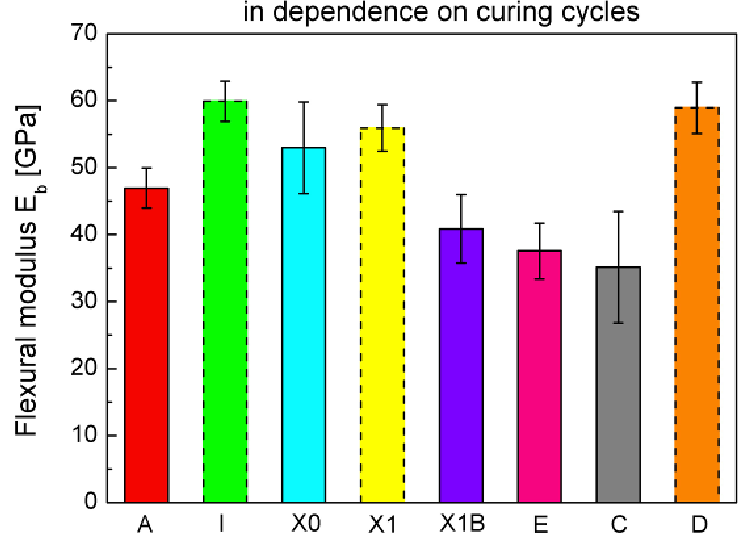

Fig 19. Flexural modulus - LFX035+carbon UD

Results for carbon UD reinforcement are shown for information purposes only. Carbon UD reinforcement Maximum flexural stress was 1054, $3 \pm 43$, $7 \mathrm{MPa}$ and flexural modulus $59,9 \pm 3 \mathrm{GPa}$ (cycle $\mathrm{I}$, which is different from cycle $\mathbf{J}$ only by vacuum level change in the region where resin has the highest viscosity $=80^{\circ} \mathrm{C}$ ) (Fig 18-19).

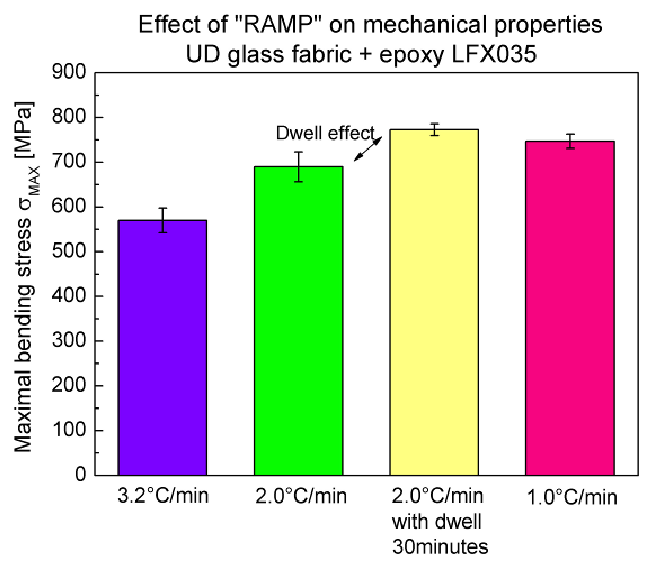

Fig 20. Maximum flexural stress - effect of RAMP

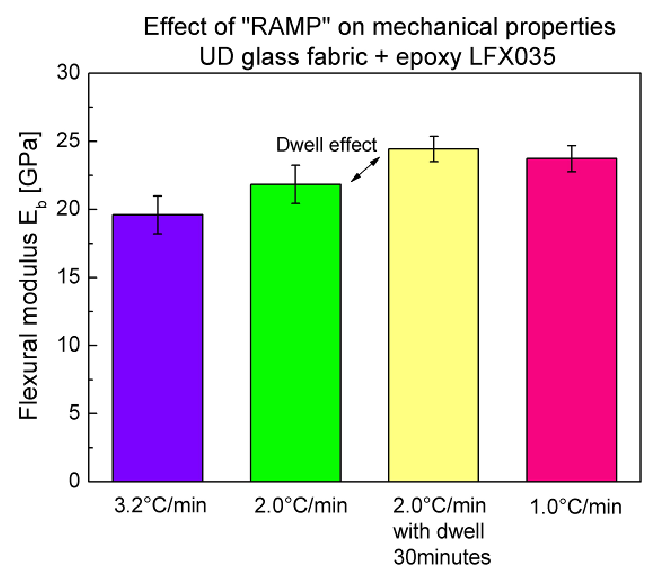

Fig 21. Flexural modulus - effect of RAMP

Ramp analysis: application of slower ramp into the curing cycle when using UD reinforcements along with epoxy film resins was effective (Fig 20-21).

Curing cycle $\mathrm{Y} 3$ has an average heat-up speed (ramp) of $2.4^{\circ} \mathrm{C} / \mathrm{min}$, and other tested curing cycles $3.2^{\circ} \mathrm{C} / \mathrm{min}$., a decrease in speed to $1^{\circ} \mathrm{C} / \mathrm{min}$ is recommended to soak resin through all layers of unidirectional fabric (to get a clear effect).

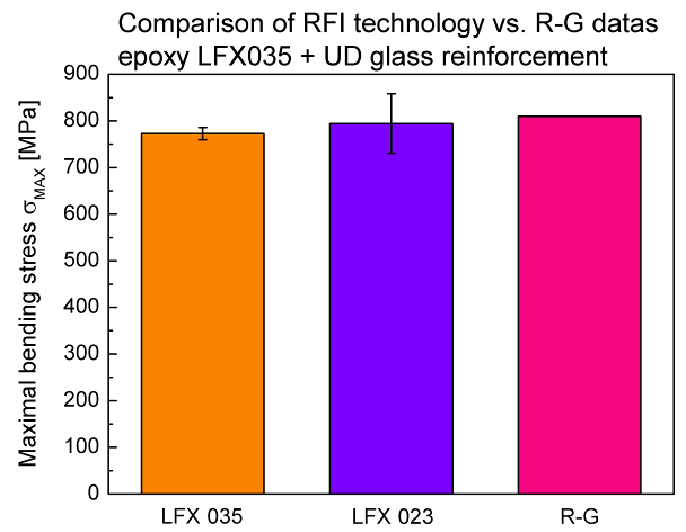

Fig 22. Maximum flexural stress - comparison of RFI technology and $R \& G$ data 


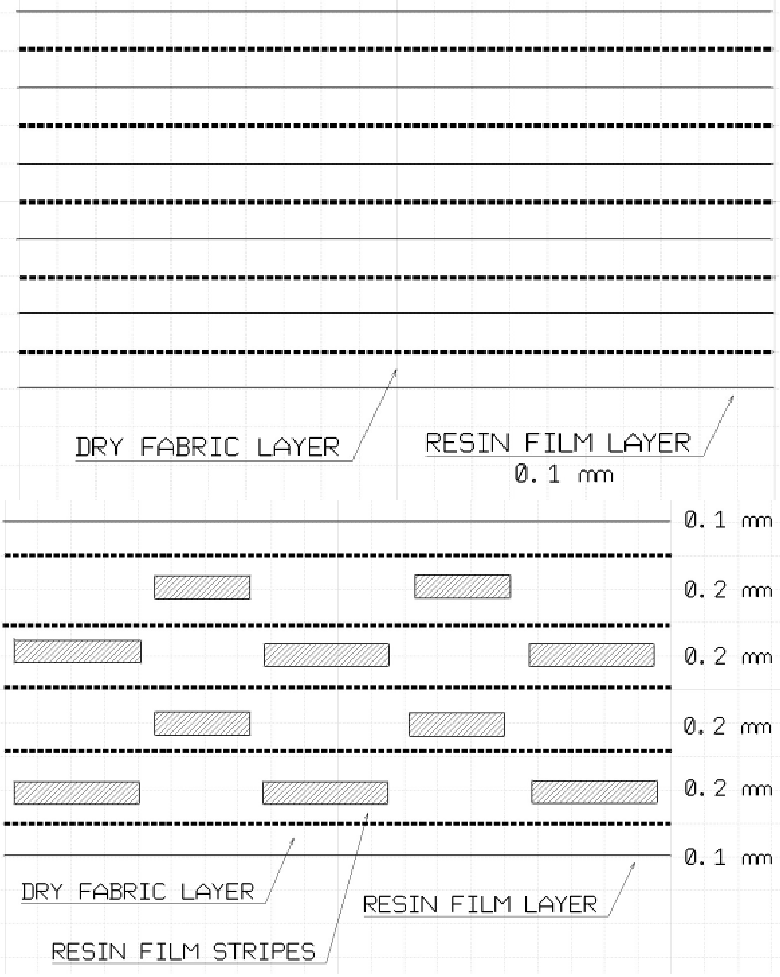

Fig 23. Typical RFI sample layout

At the start of unidirectional glass fabrics testing, preliminary wet out samples were made. With LFX023 epoxy resin it was hard to wet out the glass fabric well. That's why another epoxy resin (LFX035) was examined. To get a clearer effect, stripes of LFX023 epoxy resin were laid on UD glass fabric (see Fig 23 for lay-out system). The system contained less resin and low void content thanks to the free space among the stripes.

This formation is similar to ZPREG technology where surface ply consists of a lightweight (usually glass) fabric laminated to a dry, medium weight carbon or glass fabric using stripes of resin. The resin impregnates the lightweight fabric sufficiently to provide light tack, whilst the heavier inner ply retains a dry surface. This format ensures that air is channeled away from the tool face before the resin stripes close [1].

\section{Conclusion and discussion}

There are many potential applications for the technology in automotive and transportation (bodies, covers, side panels, and doors), aerospace (covers, doors and all type of panels) and building (tables). The main field of RFI technology is in aerospace technology where this method can lower the cost of the finished composite.

Part A: From obtained data of mechanical properties we can assume, matrix system No 1 (LFX023) has more reproducible results, with a relatively low error load. Epoxy resin system LFX023 is standard epoxy resin and is recommended for use with classic fabrics [3].

Part B: Basalt plain reinforcement seems to be acceptable instead of glass plain reinforcements. Flexural properties of Basalt hybrid fabrics are not good compared to Carbon hybrid.
This is thanks to the Basalt fabric structural components, which do not have the same mechanical properties as Carbon fiber. On the other hand, basalt hybrid composite withstands the impact test much better.

Part C: The unidirectional fabrics with new LFX035 RFI resin were tested (LFX035 was compared to LFX023). LFX035 is more liquid and therefore acceptable for the RFI infusion process where UD textiles are hard to wet-out. On mechanical testing results conclusion was made out. The most suitable curing cycles for epoxy resin LFX035 are cycles $\mathrm{J}$ and X1. They have different ramp parameters. Between them, we can choose one acceptable for us.

After evaluation of work and time effectiveness it was assumed that curing cycle $\mathrm{J}$ is more desirable for UD composites processing. The time needed to reach a curing temperature is shorter ( $1 \mathrm{hr}$. and $15 \mathrm{~min}$.) than in cycle X1 (1hr. and $40 \mathrm{~min}$.).

\section{Future work}

During 2006/2007, spinner and spinner backplate will be fabricated by RFI technology [4]. For future application of external pressure during the curing process it is planned to obtain higher mechanical properties. The relationship between compaction pressure and fiber volume fraction is very important in the RFI process since fiber volume fraction has a large influence on the mechanical properties of the composite part.

A computer simulation model of the RFI process can be used to predict resin infiltration into the preform and cure of the resin saturated preform for a given processing cycle $[6,5]$.

\section{Acknowledgments}

Appreciation is extended to 5M Company Ltd., MELTIT Ltd., and University of Defence Brno and to Doc. Ing. Klement, CSc. (IAE). This project was solved with the support of ARC (Aerospace Research Centre) BUT.

\section{References}

1. http://www.advanced-composites.com/ZPREG [online]. 2006 [q. 2006-10-05].

2. KŘÍPAL, L. Aircraft propeller nose cone made by LF-TECHNOLOGY. Proceedings of Aerospace Research Centre workshop, November 2006, Prague, Czech Republic.

3. KŘÍPAL, L.; MIHALIDES, D.; DANIEL, M. et al. Influence of matrix systems on mechanical properties of composite test specimens made by RFI technology. Proceedings of XXIII International Conference "Reinforced Plastics 2005”, 24 $4^{\text {th }}$ - 26 $6^{\text {th }}$ May 2005, Karlovy Vary, Czech Republic.

4. KŘÍPAL, L.; MIHALIDES, D.; PAVLICA, R. Mechanical properties of composite test specimens made by RFI technology. Czech 
Aerospace Proceedings. Prague: ALV Association of Aviation Manufacturers, 2006, no 2, p. 13-16 (48 tot.). ISSN 1211-877X.

5. LOOS, AC.; MacRAE JD. A process simulation model for the manufacture of a blade-stiffened panel by the Resin film infusion process. In Composites, Science and Technology. 1996, vol. 56, p. 273-289.

6. LOOS, AC.; MacRAE JD. Resin film infusion process simulation of complex wing structures. Fifth NASA/DoD Advanced Composites Technology Conference, May 1995, p.773-786.

7. MAMKIN, M. Fibre composite materials. ACA - Academic Creative Activity - student competition. Brno: Department of Mechanical Engineering, University of Defence in Brno, 2006.

8. PAVLICA, R. New technology for advanced composite structures, JEC show. In JEC composites journal. Paris, 2006, no 22, p. 57-59. INIST: 6674, 35400013574810. 0080 .

9. Website: www.5M.cz /2005 [q. 2006-10-04]. 